Organizational Nostalgia Lowers Turnover Intentions by Increasing Work Meaning:

The Moderating Role of Burnout

Leunissen, J.M., Sedikides, C., Wildschut, T., \& Cohen, T.R. (2016). Organizational Nostalgia Lowers Turnover Intentions by Increasing Work Meaning: The Moderating Role of Burnout. Journal of Occupational Health Psychology. Forthcoming 


\begin{abstract}
We report three studies addressing the relevance of organizational nostalgia for the meaning that employees ascribe to their work (work meaning). We hypothesized, and found, that organizational nostalgia enhances work meaning and thereby reduces turnover intentions. In Study 1, an employee survey, spontaneously experienced organizational nostalgia was associated with higher work meaning. In Study 2, an organizational-nostalgia induction increased work meaning, which subsequently predicted lowered turnover intentions. In Study 3, an organizational-nostalgia induction increased work meaning and thereby lowered turnover intentions, especially among employees who reported relatively high levels of burnout. When burnout is high, organizational nostalgia functions as a rich source of meaning that benefits employees' work experience.
\end{abstract}

Keywords: nostalgia, organizational nostalgia, work meaning, turnover intentions, burnout 
Organizational Nostalgia Lowers Turnover Intentions by Increasing Work Meaning: The Moderating Role of Burnout

Most people have a strong need for meaningful work (Cartwright \& Holmes, 2006; Pratt \& Ashford, 2003; Steger, Littman-Ovadia, Miller, Menger, \& Rothmann, 2013). Work meaning entails perceiving one's work as significant and meeting the psychological needs for personal growth and purpose (i.e., eudaimonic wellbeing). It entails a combination of experiencing positive meaning in one's work (i.e., the sense that one's work matters and is meaningful), seeing one's work as a path toward making meaning (i.e., the sense that one's work deepens understanding of one's self and the world), and perceiving one's work to contribute to the greater good (i.e., the sense that one can have a broader, positive impact on others through one's work) (Steger, Dik, \& Duffy, 2012).

Work meaning confers benefits to employees and their organization. For example, it fosters the sense that work is a key part of one's identity and a vital contributor to well-being (Arnold, Turner, Barling, Kelloway, \& McKee, 2007; Harpaz \& Fu, 2002). Employees who derive meaning from their work report greater job satisfaction, work unit cohesion, and organizational commitment (Kamdron, 2005; Nord, Brief, Atieh, \& Doherty, 1990; Sparks \& Schenk, 2001; Steger et al., 2012). On the other hand, low work meaning is associated with high turnover (Steger et al., 2012).

With mounting evidence pointing to the merits of work meaning for employees and organizations, it becomes critical to understand its sources. In this article, we focus on one such source: organizational nostalgia. We propose that organizational nostalgia increases work meaning and, by so doing, lowers turnover intentions. We further argue that, if organizational nostalgia replenishes work meaning, it should be particularly beneficial to employees with depleted psychological resources, that is, those with high levels of burnout. Next, we present the rationale for these predictions.

\section{Organizational Nostalgia}

According to The New Oxford Dictionary of English (1998), nostalgia is “a sentimental longing or wistful affection for the past" (p. 1266). Nostalgic recollections typically involve important personal experiences or landmark events from one's life, such as 
family traditions, relational celebrations, or cultural rituals (e.g., family holiday, graduation, wedding, birth of a child; Abeyta, Routledge, Sedikides, \& Wildschut, 2015; Holak \& Havlena, 1992; Wildschut, Sedikides, Arndt, \& Routledge, 2006). One often views the recollection through rose-tinted glasses, misses that time or person, and may even long to return to the past. As a result, one typically feels sentimental, most often happy but with a tinge of longing (Hepper, Ritchie, Sedikides, \& Wildschut, 2012). Laypersons conceptualize nostalgia as an ambivalent (but predominantly positive), social, and past-oriented emotion (Hepper et al., 2012). These lay conceptions of nostalgia are shared across cultures (Hepper et al., 2014).

We define organizational nostalgia as a sentimental longing or wistful affection for past events and aspects of one's organizational life (e.g., buildings, colleagues, leaders, technology; Gabriel, 1993). Organizational nostalgia is distinct from other forms of nostalgia currently identified, namely personal and collective nostalgia. The distinction between organizational and personal nostalgia is based on the separation between work and private domains of life (Clark, 2000; Greenhaus, Collins, \& Shaw, 2003). Employees experience their work and private lives as distinct domains. These domains are occupied at different times (e.g., work week vs. weekends) and in different places (e.g., office vs. home). We define organizational nostalgia as the nostalgic reverie that centers specifically on past experiences in the work domain (e.g., remembering fondly a company picnic or the achievement of a professional goal; Gabriel, 1993).

We further distinguish organizational nostalgia from collective nostalgia. According to Wildschut, Bruder, Robertson, Van Tilburg, and Sedikides (2014) “collective nostalgia ... is contingent upon thinking of oneself in terms of a particular social identity or as a member of a particular group (i.e., self-categorization at the collective level; Iyer \& Leach, 2009) and concerns events or objects related to it" (p. 845). These authors conceptualized collective nostalgia as a group-level emotion and proposed that it pertains specifically to past experiences shared with other in-group members (e.g., waxing nostalgic about a vacation with a group of friends or graduation celebrations with other students). By contrast, organizational nostalgia can refer to personal experiences in the work environment that were 
not shared with other in-group members (e.g., a nurse who develops a unique emotional bond with a particular patient).

In summary, organizational nostalgia differs from personal and collective nostalgia in that the recollection (1) refers to the work environment (rather than private life, as in personal nostalgia), and (2) contains the employee's recounting of personal organizational events-a recounting that may not necessarily be shared with other organizational members (as would be the case with collective nostalgia). Note that our definition is not constrained to a specific type of organization.

\section{Organizational Nostalgia Increases Work Meaning}

Pondering the psychological functions of organizational nostalgia, Gabriel (1993) proposed that it "provides a groundrock of loving memories, a life that has been worth living and a source of meaning" (p. 137). Research on personal nostalgia lends credence to Gabriel's speculation. A core psychological function of personal nostalgia is the provision of meaning in life (Hepper et al., 2012; Reid, Green, Wildschut, \& Sedikides, 2014; Routledge, Wildschut, Sedikides, Juhl, \& Arndt, 2012; Van Tilburg, Igou, \& Sedikides, 2013). Personal nostalgia fosters meaning by virtue of its capacity to strengthen social connectedness (Routledge et al., 2011; Routledge, Sedikides, Wildschut, \& Juhl, 2013). Social relationships (friends, family, partners) along with interpersonal elements or concepts (belonging, cuddles, tender moments, warmth, love) are seen as centrally defining features of nostalgia (Hepper et al., 2012, 2014). Social connectedness, in turn, is a key source of meaning in life (Baumeister, 2005; Hicks, Schlegel, \& King, 2010; Mikulincer, Florian, \& Hirschberger, 2003; Williams, 2001). Lambert et al. (2010), for instance, demonstrated that participants identified their families as the single most important source of meaning in life and ranked family above 12 other likely sources of meaning.

We extrapolate from this literature to the domain of organizational nostalgia. We argue that experiencing organizational nostalgia fosters work meaning. Qualitative interviews suggest that images of the organization as a family form the core of organizational nostalgia. Examples are nurses who bring to mind their demanding, albeit intimate and fulfilling, work environment before the hospital merged into a larger one (Gabriel, 1993); academics who 
reflect on the collegial, autonomous atmosphere in higher education before the rise of centralization and commercialization (Brown \& Humphreys, 2002; Ylijoki, 2005); and employees of a coffee shop who fondly remember the close-knit community of colleagues before their organization moved to a larger site (Milligan, 2003). The prevalence of the family metaphor and frequent references to social connectedness suggest that organizational nostalgia imbues work with meaning. This leads to our first hypothesis:

Hypothesis 1: Organizational nostalgia increases work meaning.

\section{Organizational Nostalgia Reduces Turnover Intentions via Increased Work Meaning}

Work meaning, or the lack thereof, affects organizational outcomes (Rosso et al., 2010). Here, we focus on a particularly costly outcome, namely, turnover. Turnover is costly, because investments in human resources, such as training or expertise, are lost to the organization when employees decide to leave (Ton \& Huckman, 2008; Van Dick et al., 2004). Moreover, turnover impacts those who stay behind, as team productivity decreases (Argote, Insko, Yovetich, \& Romero, 1995) and job satisfaction weakens (Krackhardt \& Porter, 1985). Indeed, overall profits fall following employee departure (Ton \& Huckman, 2008). As such, understanding the causes of turnover and retaining employees are highly relevant to organizational health. In our research, we treated turnover intentions as a proxy for turnover. Although turnover is determined by more than merely turnover intentions (e.g., the perceived availability of job alternatives), turnover intentions do have a strong influence on turnover: The correlation between turnover intentions and turnover has been meta-analytically estimated at approximately .50 (Steel \& Ovalle, 1984; Tett \& Meyer, 1993). We are not aware of research that has tested the causal link between work meaning and turnover intentions, but theoretical statements and correlational findings point to a negative association between the two (Barrick, Mount, \& Li, 2013; George \& Jones, 1996; Steger et al., 2012). In line with these overtures, we expected greater work meaning to be linked with weaker turnover intentions.

We have hypothesized so far that organizational nostalgia would increase work meaning. Based on past findings, we expect for work meaning to be associated with weaker 
turnover intentions. Taken together, we anticipate that, by virtue of its capacity to increase work meaning, organizational nostalgia will lower turnover intentions.

Hypothesis 2: Work meaning mediates the effect of organizational nostalgia on reduced turnover intentions.

Organizational Nostalgia Increases Work Meaning when Burnout Is High

We postulate that organizational nostalgia is a resource that imbues employees with work meaning. This suggests that organizational nostalgia acquires special significance when burnout is high. Burnout is a work-related condition defined as "a state of physical, emotional and mental exhaustion that results from long-term involvement in work situations that are emotionally demanding', (Schaufeli \& Greenglass, 2001, p. 501). According to the job demands-resources model, burnout develops due to (1) excessive job demands, resulting in emotional exhaustion, and (2) depleted job resources, resulting in disengagement and cynicism (Demerouti, Bakker, Nachreiner, \& Schaufeli, 2001). Burnout can affect employees from any sector (Kristensen, et al., 2005; Maslach, Schaufeli, \& Leiter, 2001; Schaufeli, \& Bakker, 2004), with estimates of up to $10 \%$ of the working population experiencing severe burnout at any given time (Schaufeli \& Buunk, 2003). Furthermore, burnout is detrimental to work experiences such as job satisfaction, absenteeism, and intentions to stay in the organization (Schaufeli \& Bakker, 2004).

Prior theory and research have linked burnout with work meaning. Maslach et al. (2001) proposed that burnout entails a process whereby "what started out as important, meaningful, and challenging work becomes unpleasant, unfulfilling, and meaningless." Survey studies indicate that burnout is negatively correlated with work meaning, as indexed by existential fulfillment (Loonstra, Brouwers, \& Tomic, 2009) and perceived work importance (Pines \& Keinan, 2005; Pines \& Zaidman, 2014). Relatedly, amotivation (a psychological state closely related to burnout; Appleton \& Hill, 2012; Lonsdale, Hodge \& Rose, 2009) is also negatively correlated with work meaning (Allan, Autin, \& Duffy, 2016). These correlational findings, though, do not establish causal direction. In the present research, we treat individual differences in burnout as an antecedent of perceived work meaning but, 
by so doing, do not rule out a bi-directional relation (we address this issue in the General Discussion).

Gabriel's (1993) early reflections on the topic implied that organizational nostalgia may be most beneficial to employees who are psychologically taxed (i.e., high burnout). He proposed that organizational nostalgia enables employees "to endure present malaise" by providing "a source of meaning in relatively meaningless situations" (pp. 133-134). Previous research on personal nostalgia lends support to this idea. Specifically, personal nostalgia is a resource that mitigates self-threat (e.g., unfavorable performance feedback), social threat (e.g., loneliness or social exclusion), and existential threat (e.g., meaninglessness of life). Examining the restorative role of nostalgia in the context of self-threat, Vess, Arndt, Routledge, Sedikides, and Wildschut (2012, Experiment 2) demonstrated that recalling a nostalgic (relative to a neutral) autobiographical event reduced self-serving performance attributions, particularly for participants who experienced failure (compared to success). Turning to social threat, Van Dijke, Wildschut, Leunissen, and Sedikides (2015, Study 5) showed that recalling a nostalgic (relative to a neutral) event increased perceived supervisor support, particularly among employees who sensed low (compared to high) social connectedness with their supervisor. In regards to existential threat, Routledge et al. (2011) found that recalling a nostalgic (relative to a neutral) event increased subjective vitality, particularly for participants who perceived life as meaningless (compared to meaningful).

Building on this evidence, we hypothesized that engaging in organizational nostalgia will increase work meaning, especially for employees who are high (compared to low) in burnout. That is, if organizational nostalgia can replenish work meaning, it should be more beneficial to employees with depleted psychological resources (i.e., high burnout) than to those with plentiful resources (i.e., low burnout).

Hypothesis 3: Organizational nostalgia increases work meaning to a greater degree among employees high (vs. low) in burnout.

Organizational Nostalgia Reduces Turnover Intentions via Increased Work Meaning when Burnout Is High 
We postulated that organizational nostalgia will raise work meaning among employees characterized by higher burnout. But what would the implications of this process be for turnover intentions? If organizational nostalgia confers work meaning benefits upon high burnout employees, these benefits may have downstream consequences in the form of lower turnover intentions (Barrick et al., 2013; George \& Jones, 1996; Steger et al., 2012). That is, such employees will express weaker intentions to leave the organization. Accordingly, work meaning should mediate the organizational-nostalgia effect on turnover intentions, but this indirect or mediated effect will be moderated by burnout (Figure 1). Edwards and Lambert (2007) described this as a direct effect and first stage moderation model, and Hayes (2013) presented it as model 8.

Hypotheses 4: Organizational nostalgia decreases turnover intentions, via increased work meaning, to a greater degree among employees high (vs. low) in burnout.

\section{Overview of Three Studies}

We tested these four hypotheses among employees in a survey and two experiments. In Study 1, a correlational study, we examined whether organizational nostalgia was positively related to work meaning (Hypotheses 1). In Study 2, we aimed to increase the internal validity of these initial findings by introducing an experimental technique. Here, we manipulated organizational nostalgia and then measured work meaning and attendant turnover intentions (thereby testing Hypotheses 1-2). In Study 3, our follow-up experiment, we examined whether organizational nostalgia influences work meaning and attendant turnover intentions more strongly among employees who are high (vs. low) in burnout. That is, organizational nostalgia should decrease turnover intentions by increasing work meaning, but this indirect or mediated effect will be stronger among employees who report high (vs. low) burnout (Hypotheses 3-4). In Study 1 and 2, we measured work meaning with the Positive Meaning subscale of the Work and Meaning Inventory, whereas, in Study 3 we included the entire Work and Meaning Inventory (Steger et al., 2012).

Study 1: Surveying the Link between Organizational Nostalgia and Work Meaning

In this preliminary study, we tested Hypothesis 1 by asking employees about their organizational nostalgia and work meaning. 


\section{Method}

Participants. We recruited 94 employed adults via Amazon's Mechanical Turk (MTurk). MTurk participants are more representative of the general public than are university samples, and results from MTurk studies are consistent with those from traditional data collection methods (Buhrmester, Kwang, \& Gosling, 2011; Mason \& Suri, 2012; Paolacci \& Chandler, 2014). All participants were U.S. residents (56 men, 38 women). The selection criteria stated that prospective participants be employed by an organization. Participants' age ranged from 18 to 61 years $(M=31.97, S D=10.73)$.

Measures. We measured organizational nostalgia with three items, preceded by the instructions: "According to the Oxford Dictionary, 'nostalgia' is defined as a 'sentimental longing for the past.' How nostalgic did you feel about your work, and the organization you work in, during the past month?" The items were: "I felt quite nostalgic about my work and organization," "I had nostalgic feelings about my work and organization," and "I felt nostalgic about my work and organization during the past month" $(\alpha=.98, M=2.48, S D=$ 1.64). We adapted these items from established assessments of personal nostalgia (Hepper et al., 2012; Wildschut et al., 2006, 2010). We measured work meaning with the 4-item Positive Meaning subscale of the Work and Meaning Inventory (WAMI; Steger et al., 2012; $\alpha=.95$, $M=4.23, S D=1.61)$. The Positive Meaning subscale is "the 'flagship' indicator" of work meaning (Steger et al., 2012, p. 333) and captures a sense that the work one is doing has personal significance, matters, and is meaningful. Sample items are: "I have found a meaningful career" and "I have a good sense of what makes my job meaningful." Participants responded to all items on a 1 (not at all) to 7 (very much) scale. We included a number of additional measures for exploratory purposes.

Results and Discussion

Consistent with Hypothesis 1, results revealed a significant positive correlation between organizational nostalgia and work meaning, $r(92)=.43, p<.001$. This finding sets the stage for examining the causal effect of organizational nostalgia on work meaning and attendant turnover intentions. 


\section{Study 2: Testing the Effect of Organizational Nostalgia on Work Meaning and}

\section{Turnover Intentions}

In Study 2, we experimentally induced organizational nostalgia (vs. control) and assessed its impact on work meaning and turnover intentions. Our key objective was to test whether organizational nostalgia increased work meaning (Hypothesis 1) and thereby reduced turnover intentions (Hypothesis 2). A secondary objective of Study 2 was to examine potential alternative mediators of the link between organizational nostalgia and turnover intentions. Personal-nostalgia inductions typically (Batcho, 2013; Cheung et al., 2013, Study 2 and 4; Hepper et al., 2012, Study 7; Stephan, Sedikides, \& Wildschut, 2012; Verplanken, 2012; Wildschut et al., 2006, Studies 5-7; Zhou et al., 2012, Study 1) but not always (Cheung et al., 2013, Study 3; Stephan et al., 2014, Studies 2-4; Zhou et al., 2012, Studies 2-4) increase positive affect (PA). Accordingly, we tested if organizational nostalgia reduced turnover intentions via increased PA or reduced negative affect (NA). That is, does organizational nostalgia reduce turnover intentions simply by increasing PA (or reducing NA) rather than by increasing work meaning? This is a pertinent question in light of evidence that (dispositional) PA is correlated with meaning in life (Hicks, Trent, Davis, \& King, 2012; King, Hicks, Krull, \& Del Gaiso, 2006; Trent, Lavelock, \& King, 2013; Steger et al., 2013). Method

Participants. We recruited and tested 127 employed adults residing in the U.S., via MTurk. The selection criteria stated that prospective participants be employed by an organization. We randomly assigned participants to the organizational-nostalgia or control condition. We excluded from the analysis one participant in the organizational-nostalgia condition who did not provide a description of a past nostalgic event they experienced in their organization, and 10 participants who failed at least one of the two attention checks we included in the survey ("Please answer this question by clicking ' 2 "" and "Please answer this question by clicking '5'"; Meade \& Bartholomew, 2012). This left 73 men and 43 women in the sample. Participants ranged in age from 20 to 64 years $(M=36.51, S D=11.91)$.

Organizational-nostalgia induction. We presented participants with a validated nostalgia manipulation, the Event Reflection Task (Sedikides, Wildschut, Routledge, Arndt, 
et al., 2015), which we amended for the current experimental objectives. In particular, we instructed participants to engage in nostalgic recollection within the context of their current employment. Participants in the organizational-nostalgia condition read: "According to the Oxford Dictionary, 'nostalgia' is defined as a 'sentimental longing for the past.' Please bring to mind a nostalgic event that you have experienced in your organization. Specifically, try to think of a past event you experienced in your organization that makes you feel most nostalgic." Participants in the control condition read: "Please bring to mind an ordinary event that you have experienced in your organization. Specifically, try to think of a past event you experienced in your organization that is ordinary." Participants in both conditions listed four keywords and then wrote a brief ( 5 min) description of the relevant event. We provide illustrative event narratives in the Appendix. Collection of the manipulation check and dependent measures followed.

Measures. Participants responded to all items on a 1 (not at all) to 7 (very much) scale. We checked the effectiveness of the organizational-nostalgia induction with three items (Hepper et al., 2012; Wildschut et al., 2006): "Right now I am feeling quite nostalgic about my organization," "Right now I am having nostalgic feelings about my organization," and "I feel nostalgic about my organization at the moment" $(\alpha=.99, M=4.08, S D=2.09)$.

We assessed work meaning with the Positive Meaning subscale of the WAMI (Steger et al., 2012; $\alpha=.94, M=4.78, S D=1.71)$. We assessed turnover intentions with five items developed by Van Dick et al. (2004). Sample items are: "I am thinking of quitting this job" and "I think I should be checking out job adverts on the daily media" ( $\alpha=.95, M=3.12, S D$ $=1.81)$. We included a number of additional measures in the study for exploratory purposes.

We measured PA and NA unobtrusively by coding the content of participants' narratives with the Linguistic Inquiry and Word Count software (LIWC; Pennebaker, Francis, \& Booth, 2001). LIWC offers a validated method for measuring verbal expression of emotion (Kahn, Tobin, Massey \& Anderson, 2007). It assigns each word and word combination to one or more linguistics categories on the basis of an internal dictionary. The total number of words falling into each category is reported as a percentage to account for differences between participants in text length. We were interested in the percentage of words falling into 
the PA (denoted in LIWC as POSEMO; e.g., "happy," "love," "joy"; $M=4.61, S D=3.32$ ) and NA (NEGEMO; e.g., "angry," "sad," "pain"; $M=1.17, S D=1.84$ ) categories.

\section{Results}

Manipulation check. We inspected the narratives that participants provided. Notably, all employees but one were able to recollect a nostalgic event about their organization, thus attesting to the prevalence of nostalgia in the workplace. An Analysis of Variance (ANOVA) yielded a significant organizational-nostalgia effect on the manipulation check index, $F(1$, $112)=45.93, p<.001, \eta^{2}=.29$. Participants in the organizational-nostalgia condition $(M=$ $5.14, S D=1.64)$ felt more nostalgic about their organization than control participants $(M=$ $2.90, S D=1.89)$. The organizational-nostalgia induction was effective.

Work meaning. Participants in the organizational-nostalgia condition $(M=5.14, S D$ $=1.55)$ reported higher work meaning than control participants $(M=4.38, S D=1.81), F(1$, $113)=5.81, p=.018, \eta_{p}^{2}=.05$. This result supports Hypothesis 1: Organizational nostalgia increases work meaning.

Turnover intentions. Participants in the organizational-nostalgia condition reported lower turnover intentions $(M=2.73, S D=1.61)$ than control participants $(M=3.54, S D=$ 1.94), $F(1,114)=5.95, p=.016, \eta_{p}^{2}=.05$. This result sets the stage for testing Hypothesis 2 .

Mediation analysis. We tested the indirect effect (denoted as $a b$ ) of organizational nostalgia on turnover intentions via work meaning (Hypothesis 2). Using Hayes's (2013) PROCESS macro (model 4; 5000 bootstraps), we found that this indirect effect was significant (i.e., the $95 \% \mathrm{CI}$ did not include 0), $a b=-.09, S E=.04,95 \% \mathrm{CI}$ [-.18; -.02]. Thus, organizational nostalgia reduced turnover intention by virtue of its capacity to increase work meaning. The results were consistent with Hypothesis 2.

Controlling for PA and NA. We used LIWC to code the content of participants' narratives for expressions of PA and NA. Participants expressed significantly more PA in the organizational-nostalgia $(M=5.56, S D=3.22)$ than in the control $(M=3.54, S D=3.12)$ condition, $F(1,113)=11.64, p=.001, \eta_{p}^{2}=.09$. Participants in the organizational-nostalgia $(M=1.00, S D=1.87)$ and control $(M=1.36, S D=1.80)$ conditions did not differ on NA, $F(1$, $113)=1.06, p=.31, \eta_{p}^{2}=.009$. The correlations of coded PA $(r[113]=-.18, p=.058)$ and 
NA $(r[113]=.09, p=.368)$ with turnover intentions were marginal and non-significant, respectively, casting doubt on their potential role as mediators. Nonetheless, we again tested the indirect effect of organizational nostalgia via work meaning on turnover intentions, with PA and NA as additional mediators (PROCESS macro; Hayes, 2013, model 4; 5000 bootstraps). The indirect effect via work meaning remained statistically significant, $a b=-.07$, $S E=.04,95 \%$ CI $[-.16 ;-.002]$. Neither the indirect effect via PA $(a b=-.02, S E=.03,95 \%$ CI $[-.09 ; .04])$ nor via NA $(a b=.002, S E=.01,95 \%$ CI [-.006; .04]) was statistically significant. Controlling for PA and NA did not diminish support for Hypothesis 2. ${ }^{1}$

\section{Summary}

The results of Study 2 were consistent with Hypotheses 1-2. An experimental induction of organizational nostalgia augmented work meaning (Hypothesis 1). By augmenting work meaning, organizational nostalgia decreased turnover intentions (Hypothesis 2). The indirect effect of organizational nostalgia on turnover intentions via work meaning remained significant after controlling for LIWC-coded PA and NA.

\section{Study 3: Burnout as a Moderator of the Effect of Organizational Nostalgia on Work}

\section{Meaning and Ensuing Turnover Intentions}

In Study 3, we assessed individual differences in burnout, induced organizational nostalgia (vs. control), and measured work meaning and turnover intentions. One of our objectives was to examine the replicability of previous findings (Hypotheses 1-2). Our main objective, however, was to extend substantially these findings (Hypotheses 3-4; Figure 1). We asked whether burnout moderates the influence of organizational nostalgia on work meaning and turnover intentions. That is, we anticipated that organizational nostalgia would enhance work meaning to a greater degree among employees high (vs. low) in burnout (Hypothesis 3) and that organizational nostalgia would reduce turnover intentions via work meaning among employees high (vs. low) in burnout (Hypothesis 4).

\footnotetext{
${ }^{1}$ We assessed organizational tenure in this study ("How long have you been in your current role in industry [in months]?"; $M=52.62, S D=67.21$, range $=2-456$ ). Organizational tenure did not significantly correlate with any of the dependent variables nor with the manipulation check. Including organizational tenure as a covariate did not alter substantively the reported results.
} 
Also, in Study 3 we addressed two methodological limitations of the preceding studies. First, in Studies 1-2, we assessed work meaning with the Positive Meaning subscale of the Work and Meaning Inventory (WAMI; Steger et al., 2012). We did so, because the positive meaning of work, or the subjective experience that one's work has personal significance (Rosso et al., 2010), constitutes the core of meaningful work. Yet, to capture its full breadth, it is important to assess all three facets of work meaning. In addition to positive meaning, this includes seeing one's work as a path toward making meaning and perceiving one's work as contributing to the greater good. These additional facets are assessed by, respectively, the Meaning Making and Greater Good WAMI subscales. In Study 3, we therefore administered the full WAMI.

Second, we re-examined the possibility that PA and/or NA explains the beneficial effects of organizational nostalgia. In Study 2, we showed that the indirect effect of organizational nostalgia on turnover intentions via work meaning remained significant when we controlled for PA and NA, as indexed by LIWC. Whereas LIWC provides an objective means of examining implicit linguistic structure and emotion words (and bypasses demand characteristics), word-level coding cannot account for the meaning or context of the entire narrative, because each word is coded independently of all the others. Accordingly, LIWC may fail to capture fully the affective responses associated with organizational nostalgia. In Study 3 , we addressed this limitation by administering self-report measures of PA and NA.

\section{Method}

Participants. We recruited and tested 129 working adults (all U.S. residents) through MTurk (69 men, 60 women). Participants ranged in age from 21 to 67 years $(M=35.38, S D$ $=10.92)$. We randomly assigned them to the organizational nostalgia or control condition. We set the same selection criteria as in Studies 1-2 and included the same two attention checks (Meade \& Bartholomew, 2012). We excluded six participants, because they answered at least one attention check incorrectly.

Materials and procedure. First, we assessed burnout with the 7-item Work Burnout subscale of the Copenhagen Burnout Inventory (Kristensen et al., 2005). This inventory treats burnout as a unitary construct with fatigue and exhaustion at its core. Hence, this assessment 
was congruent with our treatment of burnout as a syndrome characterized by "...physical, emotional and mental exhaustion“"(Schaufeli \& Greenglass, 2001, p. 501). Sample items are: "Do you feel burned out because of your work?" and "Do you feel worn out at the end of the working day?" $(\alpha=.84, M=3.48, S D=1.43)$. A Principle Component Analysis indicated that the seven items of the Work Burnout subscale loaded on a single factor with an Eigenvalue of 4.45 , explaining $64 \%$ of the variance. After we measured burnout, and following several filler items, we manipulated organizational nostalgia as in Study 2. We checked the effectiveness of the manipulation with the same three items as in Study 2 ( $\alpha$ $=.99, M=3.95, S D=2.07$ ). We assessed work meaning with the 10-item WAMI (Steger et al., 2012; $(\alpha=.95, M=4.55, S D=1.61)$. A Principle Component Analysis indicated that the 10 items loaded on a single factor with an Eigenvalue of 7.22, explaining $72.24 \%$ of the variance. We relied on established self-report measures of PA and NA (Cheung et al., 2013; Hepper et al., 2012; Wildschut et al., 2006). In particular, we used "happy" and "in a good mood" $(r[120]=.88, p<.001 ; M=5.10, S D=1.62)$ to measure PA, and "unhappy" and "sad" $(r[120]=.84, p<.001 ; M=2.07, S D=1.47)$ to measure NA. We measured turnover intentions with the same five items as in Study $2(\alpha=.96, M=3.90, S D=2.40)$. We included a number of additional measures for exploratory purposes.

\section{Results}

Manipulation check. We conducted a regression analysis with organizational nostalgia (contrast coded: $-1=$ control, 1 = organizational nostalgia), burnout (mean centered), and the Organizational Nostalgia $\times$ Burnout interaction as predictor variables. The manipulation check index was the dependent variable. The main effect of organizational nostalgia was significant, $\beta=.56, t(119)=7.35, p<.001$. Participants in the organizationalnostalgia condition $(M=5.19, S D=1.61)$ felt more nostalgic than those in the control condition $(M=2.88, S D=1.81)$. Burnout was not significantly associated with felt nostalgia, $\beta=-.06, t(119)=-.73, p=.466$. Importantly, the Organizational Nostalgia $\times$ Burnout interaction was numerically small and non-significant, indicating that organizationalnostalgia induction was effective irrespective of burnout, $\beta=.02, t(118)=.24, p=.814$. 
Work meaning. We tested whether organizational nostalgia elevated work meaning and whether burnout moderated this effect. The organizational-nostalgia main effect was significant, $\beta=.28, t(118)=3.28, p=.001$, indicating that participants who were nostalgic about their organization $(M=5.09, S D=1.32)$ reported higher work meaning than control participants $(M=4.10, S D=1.70)$. This result replicates corresponding findings from Studies 1-2 in support of Hypothesis 1. The association between burnout and work meaning was also significant, $\beta=-.23, t(118)=-2.64, p=.010$. Consistent with previous findings (e.g., Loonstra et al., 2009), higher burnout was associated with lower work meaning. Crucially, however, both main effects were qualified by a significant Organizational Nostalgia $\times$ Burnout interaction, $\beta=.19, t(117)=2.24, p=.027$ (Figure 2, top panel).

To probe the Organizational Nostalgia $\times$ Burnout interaction, we used Johnson and Neyman's (1936) regions-of-significance technique as implemented by Hayes's (2013) PROCESS macro. Consistent with Hypothesis 3, burnout moderated the positive effect of organizational nostalgia on work meaning. Organizational nostalgia (vs. control) enhanced work meaning among participants who experienced higher burnout (burnout scores equal to or greater than $-0.51 S D$ ), but not among participants who experienced low burnout (lower than $-0.51 S D)^{2}$. This result is consistent with Hypothesis 3: An infusion of organizational nostalgia diminished the negative association between burnout and work meaning.

Turnover intentions. We asked whether organizational nostalgia reduced turnover intentions and whether burnout moderated this effect. The organizational nostalgia main effect was significant, $\beta=-.20, t(119)=-2.72, p=.007$, indicating that participants who were nostalgic about their organization $(M=3.35, S D=2.08)$ had lower turnover intentions than control participants $(M=4.47, S D=2.52)$, replicating Study 2 . The association between

\footnotetext{
${ }^{2}$ A corollary of Hypothesis 3 is that, by providing a rich source of meaning, organizational nostalgia mitigates the negative impact of burnout on work meaning. That is, the negative association between burnout and work meaning should be weaker among employees who experience organizational nostalgia than among those who reflect on a neutral memory from their organizational past. Simple slopes analyses confirmed that the negative association between burnout and work meaning was weaker (and non-significant) in the organizationalnostalgia condition, $\beta=-.04, t(117)=-.37, p=.712$, than in the control condition, $\beta=-.42$, $t(117)=-3.47, p<.001$.
} 
burnout and turnover intentions was also significant, $\beta=.54, t(119)=7.23, p<.001$. Replicating previous findings (Jackson, Schwab \& Schuler, 1986; Schaufeli \& Bakker, 2004), higher burnout was associated with stronger turnover intentions. Importantly, these main effects were qualified by a significant Organizational Nostalgia $\times$ Burnout interaction, $\beta=-$ $.21, t(118)=-2.98, p=.004$ (Figure 2, bottom panel). Regions-of-significance analyses revealed that the negative effect of organizational nostalgia on turnover intentions was moderated by burnout. Organizational nostalgia reduced turnover intentions among participants with higher burnout (equal to or greater than $-0.26 S D$ ), but not among those with low burnout (lower than $-0.26 S D$ ). These results set the stage for testing Hypothesis 4.

Mediation analysis testing Hypothesis 2. Before testing Hypothesis 4 (the moderated mediation hypothesis), we re-tested Hypothesis 2 (the mediation hypothesis). For the purpose of this analysis, we focused on the effect of organizational nostalgia on turnover intentions via work meaning (irrespective of burnout). Using Hayes's (2013) PROCESS macro (model 4; 5000 bootstraps), we found that this indirect effect was significant, $a b=-.12$, $S E=.05,95 \%$ CI [-.25; -.06]. In replication of Study 2 and in support of Hypotheses 1-2, organizational nostalgia decreased turnover intentions by enhancing work meaning.

Moderated mediation analysis testing Hypothesis 4. Hypothesis 4 anticipated that organizational nostalgia decreases turnover intentions, via work meaning, to a greater degree among employees high (vs. low) in burnout. That is, work meaning should mediate the organizational-nostalgia effect on turnover intentions, but this indirect or mediated effect will be moderated by burnout (Figure 1). We used Hayes's (2013) PROCESS macro to test the indirect effect of organizational nostalgia on turnover intentions via work meaning, conditional upon burnout (model 8, 5000 bootstraps). Results were consistent with Hypothesis 4. Specifically, for employees who experienced high burnout (+1 SD), organizational nostalgia reduced turnover intentions via work meaning, $a b=-.14, S E=.06$, 95\% CI [-.29; -.05]. For employees who experienced low burnout (-1 SD), however, this indirect effect was not significant, $a b=-.03, S E=.04,95 \% \mathrm{CI}[-.12 ; .05] .^{3}$

\footnotetext{
${ }^{3}$ A corollary of Hypothesis 4 is that burnout predicts increased turnover intentions, via reduced work meaning, to a lesser degree among employees who experience organizational
} 
Generality across WAMI subscales. To ascertain the generality of our findings across all three facets of work meaning assessed by the WAMI, we conducted separate moderated mediation analyses for the Positive Meaning $(\alpha=.95, M=4.64, S D=1.77)$, Meaning Making $(\alpha=.90, M=4.43, S D=1.78)$, and Greater Good $(\alpha=.73, M=4.57, S D=$ 1.56) subscales. For employees who experienced high burnout $(+1 S D)$, organizational nostalgia reduced turnover intentions via the Positive Meaning $(a b=-.17, S E=.06,95 \% \mathrm{CI}$ $[-.32 ;-.07])$, Meaning Making $(a b=-.11, S E=.05,95 \%$ CI $[-.24 ;-.03])$, and Greater Good $(a b=-.09, S E=.04,95 \%$ CI $[-.20 ;-.03])$ subscales. For employees who experienced low burnout (-1 SD), these indirect effects were non-significant. Hence, subscale analyses supported Hypothesis $4 .^{4}$

Controlling for PA and NA. We conducted two regression analyses with PA and NA as the dependent variables. For PA, the organizational-nostalgia main effect was significant, $\beta=.26, t(117)=3.27, p=.001$. Participants who were nostalgic about their organization $(M$ $=5.62, S D=1.30)$ experienced more PA than control participants $(M=4.64, S D=1.74)$. The association between burnout and PA was also significant, $\beta=-.41, t(117)=-5.16, p<.001$. Replicating previous findings (Little, Simmons, \& Nelson, 2007), higher burnout was associated with lower PA. The Organizational Nostalgia $\times$ Burnout interaction was marginal, $\beta=.14, t(117)=1.74, p=.085$ (Figure 3, top panel). Regions-of-significance analyses

nostalgia than among those who reflect on a neutral memory from their organizational past. Simple slopes analyses indeed indicated that the positive relation between burnout and turnover intentions was weaker (yet still significant) in the organizational-nostalgia condition, $\beta=.33, t(118)=3.31, p=.001$, than in the control condition, $\beta=.76, t(118)=7.32, p$ $<.001$. Moderated mediation analyses further indicated that the indirect effect of burnout on turnover intentions via reduced work meaning was smaller (and non-significant) in the organizational-nostalgia condition, $a b=.01, S E=.04,95 \%$ CI $[-.06 ; .09]$ than in the control condition, $a b=.13, S E=.06,95 \% \mathrm{CI}[.04 ; .29]$. Thus, recalling a nostalgic (vs. neutral) organizational memory weakened substantially the positive association between burnout and turnover intentions.

${ }^{4}$ Subscale analyses also supported the corollary of Hypothesis 4. In the control condition, burnout predicted increased turnover intentions via the Positive Meaning ( $a b=.16, S E=.07$, $95 \%$ CI $[.06 ; .34])$, Meaning Making $(a b=.09, S E=.05,95 \%$ CI $[.02 ; .24])$, and Greater Good $(a b=.07, S E=.05,95 \%$ CI $[.01 ; .19])$ subscales. In the organizational-nostalgia condition, these indirect effects were reduced and non-significant. 
revealed that organizational nostalgia increased PA among participants with high burnout (equal to or greater than $-0.58 S D$ ), but not among those with low burnout (lower than -0.58 $S D)$. From a different angle, there was a negative relation between burnout and PA in the control condition, $\beta=-.55, t(117)=-4.86, p<.001$, which was attenuated (albeit still significant) in the organizational-nostalgia condition, $\beta=-.28, t(117)=-2.55, p=.012$.

For NA, we obtained a complementary (i.e., mirror image) pattern of results. The organizational-nostalgia main effect was marginal, $\beta=-.14, t(118)=-1.70, p=.092$. Participants who were nostalgic about their organization $(M=1.78, S D=1.25)$ tended to experience less NA than control participants $(M=2.32, S D=1.61)$. The association between burnout and NA was significant, $\beta=.46, t(118)=5.78, p<.001$. Consistent with prior research (Little et al., 2007), higher burnout was associated with higher NA. The Organizational Nostalgia $\times$ Burnout interaction was significant, $\beta=-.17, t(117)=-2.16, p$ $=.033$ (Figure 3, bottom panel). Regions-of-significance analyses revealed that organizational nostalgia reduced NA among participants with higher burnout (equal to or greater than $0.13 S D$ ), but not among those with low burnout (lower than $0.13 S D$ ). From another viewpoint, there was a positive relation between burnout and NA in the control condition, $\beta=.64, t(117)=5.62, p<.001$, which was attenuated (yet still significant) in the organizational-nostalgia condition, $\beta=.30, t(117)=2.73, p=.007$.

Both self-reported PA $(r[119]=-.43, p<.001)$ and NA $(r[119]=.48, p<.001)$ were significantly correlated with turnover intentions, underscoring their potential role as mediators. We therefore again tested the conditional (upon burnout) indirect effects of organizational nostalgia via work meaning (full WAMI) on turnover intentions, with PA and NA as additional mediators. For employees who experienced high burnout $(+1 S D)$, the indirect effect of organizational nostalgia on turnover intentions via work meaning remained significant, $a b=-.09, S E=.05,95 \%$ CI [-.21; -.02]. For employees who experienced low burnout (-1 SD), this indirect effect remained non-significant, $a b=.002, S E=.05,95 \%$ CI [$.09 ; .10]$. 
Controlling for PA and NA did not diminish support for Hypothesis 4. ${ }^{5}$ These analyses did, however, reveal an additional conditional indirect effect via NA (but not PA). When burnout was high $(+1 S D)$, there was a significant indirect effect of organizational nostalgia on turnover intentions via NA, $a b=-.07, S E=.05,95 \%$ CI [-.20; -.006].

Organizational nostalgia reduced NA and thereby reduced turnover intentions. When burnout was low (-1 SD), this indirect effect via NA was not significant, $a b=.006, S E=.02,95 \% \mathrm{CI}$ $[-.02 ; .06]$. Looked at from a different angle, the indirect effect of burnout on turnover intentions via NA was smaller (albeit still significant) in the organizational-nostalgia condition, $a b=.06, S E=.04,95 \% \mathrm{CI}[.01 ; .16]$ than in the control condition, $a b=.13, S E$ $=.07,95 \%$ CI $[.02 ; .31]$.

\section{Summary}

Study 3 results were consistent with Hypotheses 1-4. Replicating Study 2, an experimental induction of organizational nostalgia augmented work meaning (Hypothesis 1) and thereby decreased turnover intentions (Hypothesis 2). Furthermore, organizational nostalgia augmented work meaning to a greater degree among employees with higher burnout (Hypothesis 3). Finally, organizational nostalgia decreased turnover intentions, via work meaning, only when burnout was high (Hypothesis 4). Controlling for PA and NA did not diminish support for Hypothesis 4, but did reveal an additional indirect effect via NE when burnout was high. We turn to the latter finding in the General Discussion. We relied in this study, and in Study 2, on a measurement-of-mediation design. Although informative, this type of design does not allow us to draw definite conclusions on the causal ordering of our measured variables (i.e., burnout, work meaning, and turnover intentions). We discuss this limitation in the General Discussion. In all, among employees with higher burnout, organizational nostalgia reduced turnover intentions by increasing work meaning and reducing NA.

\footnotetext{
${ }^{5}$ When we included PA and NA as additional mediators, the indirect effect of burnout on turnover intentions via reduced work meaning remained smaller (and non-significant) in the organizational-nostalgia condition, $a b=.01, S E=.04,95 \%$ CI $[-.05 ; .09]$, than in the control condition, $a b=.13, S E=.07,95 \%$ CI $[.03 ; .29]$. This supports the corollary of Hypothesis 4.
} 


\section{General Discussion}

Work meaning enriches one's occupational environment (Barrick et al., 2013; Steger et al., 2012). For example, work meaning is associated with placing higher value on one's job, being satisfied with it, and being committed to the organization (Kamdron, 2005; Nord et al., 1990; Sparks \& Schenk, 2001; Steger et al., 2012). In contrast, lack of work meaning is associated with stronger intentions to leave the organization (Steger et al., 2012). Therefore, understanding the sources of work meaning is pivotal both to employee well-being and optimal organizational functioning. Here, we focused on one likely source: organizational nostalgia. We examined, in three studies, the role of organizational nostalgia in enhancing work meaning and weakening turnover intentions, especially among burned-out employees.

\section{Summary of Findings}

We offered four hypotheses and obtained consistent support for them across three studies. First, we expected that organizational nostalgia would increase work meaning (Hypothesis 1). Using a survey methodology in Study 1, we measured organizational nostalgia and work meaning. As hypothesized, organizational nostalgia was associated with higher work meaning. We conceptually replicated this link in Studies 2 and 3. Here, experimentally induced organizational nostalgia increased work meaning and decreased turnover intentions. Consistent with Hypothesis 2, work meaning mediated organizational nostalgia's reduction of turnover intentions.

Furthermore, we expected that organizational nostalgia would acquire special significance when burnout is high. This idea was based on theoretical speculation that organizational nostalgia serves "to make the present more bearable" for those who are "low, infirm, or powerless" (Gabriel, 1993, p. 131) and on empirical evidence that personal nostalgia mitigates psychological threats (Routledge et al., 2011; Van Dijke et al., 2015; Vess et al., 2012). Accordingly, we hypothesized that the positive influence of organizational nostalgia on work meaning would manifest most strongly when burnout is high (vs. low) (Hypothesis 3). Finally, based on evidence for a link between work meaning and turnover intentions (Barrick et al., 2013; George \& Jones, 1996; Steger et al., 2012), we also expected that organizational nostalgia would decrease turnover intentions, via work meaning, to a 
greater degree among high-burnout employees (Hypothesis 4).

Study 3 supported Hypotheses 3 and 4. We showed that organizational nostalgia serves as a resource. By instilling work meaning, it helps employees to cope with the psychological adversity of burnout and to adopt an arguably more constructive stance toward their organization (i.e., express lower turnover intentions). Additionally, consistent with prior research (Loonstra et al., 2009; Schaufeli \& Bakker, 2004), we demonstrated that burnout was negatively associated with work meaning and positively associated with turnover intentions. However, these deleterious associations were significantly weakened when employees engaged in organizational nostalgia. These findings emphasize the potential of organizational nostalgia as an intervention to mitigate burnout.

Studies 2-3 assessed PA and NA. In both studies, organizational-nostalgia (vs. control) increased PA, but did not significantly affect NA. This basic pattern of results is consistent with prior evidence that personal-nostalgia inductions typically increase PA, but have little impact on NA (Sedikides, Wildschut, Routledge, Arndt, et al., 2015). In this light, it is noteworthy that burnout moderated the affective signature of organizational nostalgia in Study 3. To be precise, organizational nostalgia (vs. control) significantly reduced NA, but only when burnout was high (Figure 3). Reduced NA, in turn, translated into reduced turnover intentions. To the extent that turnover is a flight response, these findings are consistent with the notion that negative emotions narrow individuals' thought-action repertoires by triggering specific action tendencies (e.g., fight, flee; Fredrickson \& Branigan, 2005). This could explain why NA, instead of PA, mediated the effect of organizational nostalgia on reduced turnover intentions when burnout was high.

From another viewpoint, Study 3 also obtained evidence that burnout predicted increased turnover intention, via NA, in the control condition, but not in the organizationalnostalgia condition. Prior research on the downstream consequences of burnout-induced NA is limited. Gillet, Vallerand, Lafrenière, and Bureau (2013) showed that NA mediated the link between amotivation and performance on an anagrams task. Our evidence indicates that organizational-nostalgia will attenuate this indirect effect of amotivation on performance via NA. This is a promising research direction. 
To be sure, we do not suggest that PA is unimportant in organizational context. According to broaden-and-build theory (Fredrickson, 1998), PA helps individuals to expand their thought-action repertoires and allocate more cognitive resources to the task at hand, resulting in performance benefits (Fredrickson \& Branigan, 2005). Consistent with this view, individuals indeed perform better when they experience PA (Amabile, Barsade, Mueller, \& Staw, 2005; Isen, Daubman, \& Nowicki, 1987; Wright, Cropanzano, \& Meyer, 2004). These beneficial effects of PA are likely to be more apparent for complex cognitive tasks than for well-structured procedural tasks (Gillet et al., 2013; McGraw, 1978). Future research would therefore also do well to examine if, by virtue of its capacity to increase PA, organizational nostalgia enhances task performance, particularly when burnout is high and tasks are cognitively demanding.

\section{Implications}

The findings contribute to scholarly understanding of work meaning by identifying a new source of it, namely organizational nostalgia. Prior investigations have identified several antecedents to work meaning, including job involvement (Brown, 1996) and job design (Hackman \& Oldham, 1976), but have largely overlooked the role of discrete emotions in shaping and influencing work meaning (Rosso et al., 2010). Our findings complement this literature by demonstrating that the discrete emotion of nostalgia augments work meaning.

The current research also injects much needed empirical evidence into the debate on the value of organizational nostalgia. To date, the scarce, qualitative literature offers conflicting perspectives. On the one hand, critics have suggested that "the anti-critical thrust of nostalgia" (DaSilva \& Faught, 1982, p. 47) serves the status quo and maintains social inequality (Natali, 2004; Rosaldo, 1989). In this perspective, organizational nostalgia is "an active tool in the hands of the management" that can be "flexibly employed to buttress arguments for change or inertia" (Strangleman, 1999, p. 743). On the other hand, scholars have cast a more positive light on nostalgia by proposing that it safeguards treasured organizational values and traditions (Brown \& Humphreys, 2002; Gabriel, 1993; Milligan, 2003). In this perspective, "by keeping the core morals and values of the local tradition alive," organizational nostalgia can "inspire active counteraction against the prevailing working 
conditions" (Ylijoki, 2005, p. 573). On balance, our findings are more compatible with the latter perspective. To the extent that organizational nostalgia prevents burnout-induced turnover, it contributes to retention of employees who are familiar with the organization's past, its traditions, and core values. Organizational nostalgia, then, can motivate employees to stand their ground rather than capitulate in the face of organizational turmoil. Organizational nostalgia is a motivational force (Sedikides \& Wildschut, 2016a,b).

Our findings indicate that organizational nostalgia is relatively easy to induce. As such, it can be an integral part of intervention programs to support employees during times of organizational hardship (e.g., budget cuts, reorganizations). Likewise, organizational nostalgia can provide the basis to develop burnout prevention practices (Schaufeli \& Buunk, 2003). Given that organizational nostalgia did not reduce work meaning for those low in burnout (and increased it for those high in burnout), it could be a risk-free intervention to implement organization-wide. Organizations may actively foster a family atmosphere (Gabriel, 1993) and rituals (e.g., summer picnics, Christmas parties) that are likely to be remembered nostalgically (Abeyta et al., 2015; Wildschut et al., 2006) and, thus, to serve as a repository of organizational meaning. Organizational meaning was negatively associated with turnover intentions in our studies, and may also positively influence closely related outcomes such as organizational commitment and job satisfaction (Blau \& Boal, 1987). Stimulating organizational nostalgia may seem self-serving from the perspective of organizations, but organizational commitment and reduced turnover also facilitates employee career advancement (Podsakoff, Whiting, Podsakoff, \& Blume, 2009). Thus, organizational nostalgia may benefit employees and organizations alike.

\section{Limitations and Future Directions}

The results of these studies need to be considered in light of a number of limitations, each of which opens up novel empirical directions. To begin, because we measured (rather than manipulated) burnout, we are unable to make causal assertions regarding its associations with work meaning and turnover intentions. Whereas some scholars propose that burnout (or the closely allied state of amotivation) is an antecedent of low work meaning (Allan et al., 2016), others favor the alternative sequence whereby low work meaning leads to burnout 
(Pines \& Keinan, 2005; Pines \& Zaidman, 2014), and still others raise the possibility of a reciprocal relation (Loonstra et al., 2009). The last possibility suggests that, by increasing work meaning, organizational nostalgia may initiate a virtuous upward cycle between increased meaning and reduced burnout, resulting in the gradual reversal of burnout. Testing these non-recursive effects between work meaning and burnout calls for longitudinal and experimental designs.

Related to the previous limitation, Study 2 and 3 used a measurement-of-mediation design. The limitations of this design are well documented (Bullock et al., 2010). Nevertheless, we regard the mediation analyses of Studies 2-3 as informative, because they placed the hypothesized model (Figure 1) at risk (Fiedler et al., 2011). That is, the postulated causal chain comprised several links. Failure of even a single link would have invalidated the hypothesized model. Future research should incorporate experimental-causal-chain designs (Spencer et al. 2005). Here, a researcher would manipulate work meaning directly and examine its downstream consequence on turnover intentions. Longitudinal designs could also address these issues.

In addition, we need to attain a better understanding of the triggers of organizational nostalgia. People recruit personal nostalgia when they experience negative psychological states such as low self-esteem (Vess et al., 2012), loneliness (Zhou et al., 2008), discontinuity between their past and their present (Sedikides, Wildschut, Routledge, \& Arndt, 2015), or boredom (Van Tilburg et al., 2013). Personal nostalgia helps to alleviate these discomforting states by fostering a sense of self-positivity, social support, continuity between one's past and one's present, and interest, respectively. We expect adverse situations in an organizational context (e.g., budget cuts) to increase organizational nostalgia. As an example of such adverse situations, qualitative research has suggested that perceived loss of academic autonomy and freedom is associated with higher organizational nostalgia (Ylijoki, 2005). We expect not only for employees to become more nostalgic in these adverse situations, but also for organizational nostalgia to offset accompanying discomforting psychological states by elevating self-esteem, social connectedness (i.e., social bonds, family atmosphere), selfcontinuity, or interest, respectively. Moreover, researchers may investigate situations in 
which organizational nostalgia can have adverse effects on employee well-being. For example, organizational nostalgia in the wake of organizational mergers or organizational change may hinder adjustment of employees to the new work situation, as an excessive focus on the old situation may impede adjustment to the new. Hence, future research would do well to address both the potential pros and cons of organizational nostalgia for employee wellbeing.

Finally, although we showed that organizational nostalgia increases work meaning, we have not fully clarified the mechanisms by which it does so. We identified social connectedness as a likely candidate. Personal nostalgia bolsters social connectedness (Van Dijke et al., 2015; Wildschut et al., 2006) and augments meaning in life via social connectedness (Routledge et al., 2011). Previous theorizing has also pointed to the relevance of social connectedness as a source of work meaning (Gabriel, 1993; Wrzesniewski, Dutton, \& Debebe, 2003).

\section{Coda}

Considering one's work to be meaningful is an essential part of well-being at work. Our research highlighted an effective, relatively effortless, and easily implementable way to foster work meaning: organizational nostalgia. We hope that the findings spark greater interest in the role of organizational nostalgia, and more generally of emotions, in work meaning. 
References

Abeyta, A., Routledge, C., Roylance, C., Wildschut, R. T., \& Sedikides, C. (2015). Attachmentrelated avoidance and the social content of nostalgic memories. Journal of Social and Personal Relationships, 32, 406-413. doi:10.1177/0265407514533770

Allan, B. A., Autin, K. L., \& Duffy, R. D. (2016). Self-determination and meaningful work: Exploring socioeconomic constraints. Frontiers in Psychology, 7, 1-9. doi:10.3389/fpsyg.2016.00071

Amabile, T. M., Barsade, S. G., Mueller, J. S., \& Staw, B. M. (2005). Affect and creativity at work. Administrative Science Quarterly, 50, 367-403. doi:10.2189/asqu.2005.50.3.367

Appleton, P. R., \& Hill, A. P. (2012). Perfectionism and athlete burnout in junior elite athletes: The mediating role of motivation regulations. Journal of Clinical Sports Psychology, 6, 129-145.

Argote, L., Insko, C. A., Yovetich, N., \& Romero, A. A. (1995). Group learning curves: The effects of turnover and task complexity on group performance. Journal of Applied Social Psychology, 25, 512-529. doi:10.1111/j.1559-1816.1995.tb01765.x

Arnold, K. A., Turner, N., Barling, J., Kelloway, E. K., \& McKee, M. C. (2007). Transformational leadership and psychological well-being: The mediating role of meaningful work. Journal of Occupational Health Psychology, 12, 193-203. doi:10.1037/1076-8998.12.3.193

Barrick, M. R., Mount, M. K., \& Li, N. (2013). The theory of purposeful work behavior: The role of personality, higher-order goals, and job characteristics. Academy of Management Review, 38, 132-153. doi:10.5465/amr.2010.0479

Batcho, K. I. (2013). Nostalgia: Retreat or support in difficult times? American Journal of Psychology, 126, 355-367. doi:10.5406/amerjpsyc.126.3.0355

Baumeister, R. (2005). Rejected and alone. The Psychologist, 18, 732-735.

Blau, G. J., \& Boal, K. B. (1987). Conceptualizing how job involvement and organizational commitment affect turnover and absenteeism. Academy of Management Review, 12, 288-300. doi:10.5465/amr.1987.4307844

Brown, A. D., \& Humphreys, M. (2002). Nostalgia and the narrativization of identity: A Turkish case study. British Journal of Management, 13, 141-159. doi: 10.1111/1467-8551.00228 
Buhrmester, M., Kwang, T., \& Gosling, S. D. (2011). Amazon's Mechanical Turk: A new source of inexpensive, yet high-quality, data? Perspectives on Psychological Science, 6, 3-5. doi:10.1177/1745691610393980

Bullock, J. G., Green, D. P., \& Ha, S. E. (2010). Yes, but what's the mechanism? (don't expect an easy answer). Journal of Personality and Social Psychology, 98, 550-558. doi:10.1037/a0018933

Cartwright, S., \& Holmes, N. (2006). The meaning of work: The challenge of regaining employee engagement and reducing cynicism. Human Resource Management Review, 16, 199-208. doi:10.1016/j.hrmr.2006.03.012

Cheung, W. Y. Wildschut, T., Sedikides, C., Hepper, E. G., Arndt, J. \& Vingerhoets, A. J. J. M. (2013). Back to the future: Nostalgia increases optimism. Personality and Social Psychology Bulletin, 39, 1484-1496. doi:10.1177/0146167213499187

Clark, S. C. (2000). Work/family border theory: A new theory of work/family balance. Human Relations, 53, 747-770. doi:10.1177/0018726700536001

DaSilva, F. B., \& Faught, J. (1982). Nostalgia: A sphere and process of contemporary ideology. Qualitative Sociology, 5, 47-61. doi: 10.1007/bf01006418

Demerouti, E., Bakker, A. B., Nachreiner, F., \& Schaufeli, W. B. (2001). The job demandsresources model of burnout. Journal of Applied Psychology, 86, 499-512. doi:10.1037//00219010.86 .3 .499

Edwards, J. R., \& Lambert, L. S. (2007). Methods for integrating moderation and mediation: A general analytical framework using moderated path analysis. Psychological Methods, 12, 122. doi:10.1037/1082-989x.12.1.1

Fiedler, K., Schott, M., \& Meiser, T. (2011). What mediation analysis can (not) do. Journal of Experimental Social Psychology, 47, 1231-1236. doi:10.1016/j.jesp.2011.05.007

Fredrickson, B. L. (1998). What good are positive emotions? Review of General Psychology, 2, 300-319. doi:10.1037/1089-2680.2.3.300

Fredrickson, B. L., \& Branigan, C. (2005). Positive emotions broaden the scope of attention and thought-action repertoires. Cognition \& Emotion, 19, 313-332.

doi:10.1080/02699930441000238 
Gabriel, Y. (1993). Organizational nostalgia: reflections on 'The Golden Age.' In S. Fineman (Ed.), Emotion in organizations (pp. 118-141). London, UK: Sage.

George, J. M., \& Jones, G. R. (1996). The experience of work and turnover intentions: interactive effects of value attainment, job satisfaction, and positive mood. Journal of Applied Psychology, 81, 318-325. doi:10.1037/0021-9010.81.3.318.

Gillet, N., Vallerand, R. J., Lafrenière, M-A. K., Bureau, J. S. (2013). The mediating role of positive and negative affect in the situational motivation-performance relationship. Motivation and Emotion, 37, 465-479. doi:10.1007/s11031-012-9314-5

Greenhaus, J. H., Collins, K. M., \& Shaw, J. D. (2003). The relation between work-family balance and quality of life. Journal of Vocational Behavior, 63, 510-531. doi:10.1016/S00018791(02)00042-8

Hackman, J. R., \& Oldham, G. R. (1976). Motivation through the design of work: Test of a theory. Organizational behavior and human performance, 16, 250-279. doi:10.1016/00305073(76)90016-7

Harpaz, I., \& Fu, X. (2002). The structure of the meaning of work: A relative stability amidst change. Human Relations, 55, 639-667. doi:10.1177/0018726702556002

Hayes, A. F. (2013). Introduction to mediation, moderation, and conditional process analysis: A regression-based approach. Guilford Press.

Hepper, E. G., Ritchie, T. D., Sedikides, C., \& Wildschut, T. (2012). Odyssey's end: Lay conceptions of nostalgia reflect its original Homeric meaning. Emotion, 12, 102-119. doi: $10.1037 / \mathrm{a} 0025167$

Hepper, E. G., Wildschut, T., Sedikides, C., Ritchie, T. D., Yung, Y.-F., Hansen, N., .. \& Zhou, X. (2014). Pancultural nostalgia: Prototypical conceptions across cultures. Emotion, 14, 733-747. doi:10.1037/a0036790

Hicks, J. A., Schlegel, R. J., \& King, L. A. (2010). Social threats, happiness, and the dynamics of meaning in life judgments. Personality and Social Psychology Bulletin, 36, 1305-1317. doi:10.1177/0146167210381650 
Hicks, J. A., Trent, J., Davis, W., \& King, L. A. (2012). Positive affect, meaning in life, and future time perspective: An application of Socioemotional Selectivity Theory. Psychology and Aging, 27, 181-189. doi:10.1037/a0023965

Holak, S. L., \& Havlena, W. J. (1992). Nostalgia: An exploratory study of themes and emotions in the nostalgic experience. Advances in Consumer Research, 19, 380-386.

Isen, A. M., Daubman, K. A., \& Nowicki, G. P. (1987). Positive affect facilitates creative problem solving. Journal of Personality and Social Psychology, 52, 1122-1131. doi:10.1037//00223514.52.6.1122

Iyer, A., \& Leach, C. W. (2009). Emotion in inter-group relations. European Review of Social Psychology, 19, 86 -125. doi:10.1080/10463280802079738

Jackson, S. E., Schwab, R. L., \& Schuler, R. S. (1986). Toward an understanding of the burnout phenomenon. Journal of Applied Psychology, 71, 630-640. doi: 10.1037/0021-9010.71.4.630

Johnson, P. O., \& Neyman, J. (1936). Tests of certain linear hypotheses and their application to some educational problems. Statistical Research Memoirs, 1, 57-93.

Kahn, J. H., Tobin, R. M., Massey, A. E., \& Anderson, J. A. (2007). Measuring emotional expression with the linguistic inquiry and word count. American Journal of Psychology, 120, 263-286.

Kamdron, T. (2005). Work motivation and job satisfaction of Estonian higher officials. International Journal of Public Administration, 28, 1211-1240. doi:10.1080/01900690500241085

King, L. A., Hicks, J. A., Krull, J., \& Del Gaiso, A. K. (2006). Positive affect and the experience of meaning in life. Journal of Personality and Social Psychology, 90, 179-196. doi:10.1037/0022-3514.90.1.179

Krackhardt, D., \& Porter, L. W. (1985). When friends leave: A structural analysis of the relationship between turnover and stayers' attitudes. Administrative Science Quarterly, 30, $242-261$.

Kristensen, T. S., Borritz, M., Villadsen, E., \& Christensen, K. B. (2005). The Copenhagen Burnout Inventory: A new tool for the assessment of burnout. Work \& Stress, 19, 192-207. doi:10.1080/02678370500297720 
Lambert, N. M., Stillman, T. F., Baumeister, R. F., Fincham, F. D., Hicks, J. A., \& Graham, S. M. (2010). Family as a salient source of meaning in young adulthood. Journal of Positive Psychology, 5, 367-376. doi:10.1080/17439760.2010.516616

Little, L. M., Simmons, B. L., \& Nelson, D. L. (2007). Health among leaders: Positive and negative affect, engagement and burnout, forgiveness and revenge. Journal of Management Studies, 44, 243-260. doi:10.1111/j.1467-6486.2007.00687.x

Lonsdale, C., Hodge, K., \& Rose, E. (2009). Athlete burnout in elite sport: A self-determination perspective. Journal of Sports Sciences, 27, 785-795. doi: 10.1080/02640410902929366

Loonstra, B., Brouwers, A., \& Tomic, W. (2009). Feelings of existential fulfilment and burnout among secondary school teachers. Teaching and Teacher Education, 25, 752-757. doi:10.1016/j.tate.2009.01.002

Maslach, C., Schaufeli, W. B., \& Leiter, M. P. (2001). Job burnout. Annual Review of Psychology, 52, 397-422. doi:10.1146/annurev.psych.52.1.397

Mason, W., \& Suri, S. (2012). Conducting behavioral research on Amazon's Mechanical Turk. Behavioral Research Methods, 44, 1-23. doi:10.3758/s13428-011-0124-6

McGraw, K. O. (1978). The detrimental effects of reward on performance, a literature review and a prediction model. In M. R. Lepper \& D. Greene (Eds.), The hidden costs of rewards, new perspectives on the psychology of human motivation (pp. 33-60). Hillsdale, NJ: Lawrence Erlbaum Associates.

Meade, A. W., \& Bartholomew, S. (2012). Identifying careless responses in survey data. Psychological Methods, 17(3), 437-455. doi:10.1037/a0028085

Mikulincer, M., Florian, V., \& Hirschberger, G. (2003). The existential function of close relationships: Introducing death into the science of love. Personality and Social Psychology Review, 7, 20-40. doi:10.1207/S15327957PSPR0701_2

Milligan, M. J. (2003). Displacement and identity discontinuity: The role of nostalgia in establishing new identity categories. Symbolic Interaction, 26, 381-403. doi:10.1525/si.2003.26.3.381

Natali, M. P. (2004). History and the politics of nostalgia. Iowa Journal of Cultural Studies, 5, 1025. 
Nord, W. R., Brief, A. P., Atieh, J. M., \& Doherty, E. M. (1990). Studying meanings of work: The case of work values. In A. Brief \& W. Nord (Eds.), Meanings of occupational work: A collection of essays (pp. 21-64). Lexington, MA: Lexington Books.

Paolacci, G., \& Chandler, J. (2014). Inside the Turk: Understanding Mechanical Turk as a participant pool. Current Directions in Psychological Science, 23, 184-188. doi:10.1177/0963721414531598

Pennebaker, J. W., Francis, M. E., \& Booth, R. J. (2001). Linguistic Inquiry and Word Count: LIWC2001 [Computer software and manual]. Mahwah, NJ: Lawrence Erlbaum.

Pines, A. M., \& Keinan, G. (2005). Stress and burnout: The significant difference. Personality and Individual Differences, 39, 625-635. doi:10.1016/j.paid.2005.02.009

Pines A. M., \& Zaidman, N. (2014). Stress and burnout in bicultural teams in hi-tech industry. British Journal of Management, 25, 819-832. doi:10.1111/1467-8551.12056

Podsakoff, N. P., Whiting, S. W., Podsakoff, P. M., \& Blume, B. D. (2009). Individual- and organizational-level consequences of organizational citizenship behaviors: A meta-analysis. Journal of Applied Psychology, 94, 122-141.

Pratt, M. G, \& Ashforth, B. E. (2003). Fostering meaningfulness in working and at work. In K. S. Cameron, J. E. Dutton, \& R. E. Quinn (Eds.), Positive organizational scholarship: Foundations of a new discipline (pp. 309-327). San Francisco, CA: Berrett-Koehler Publishers, Inc.

Reid, C. A., Green, J. D., Wildschut, T., \& Sedikides, C. (2015). Scent-evoked nostalgia. Memory, 23, 157-166. doi:10.1080/09658211.2013.876048

Rosaldo, R. (1989). Imperialist nostalgia. Representations, 26, 107-122.

Rosso, B. D., Dekas, K. H., \& Wrzesniewski, A. (2010). On the meaning of work: A theoretical integration and review. Research in Organizational Behavior, 30, 91-127. doi:10.1016/j.riob.2010.09.001

Routledge, C., Arndt, J., Wildschut, T., Sedikides, C. M., Hart, C., Juhl, J., Vingerhoets, A. J. J. M., \& Schlotz, W. (2011). The past makes the present meaningful: Nostalgia as an existential resource. Journal of Personality and Social Psychology, 101, 638-652. doi:10.1037/a0024292 
Routledge, C., Sedikides, C., Wildschut, T., \& Juhl, J. (2013). Finding meaning in the past:

Nostalgia as an existential resource. In K. Markman, T. Proulx, \& M. Lindberg (Eds.), The psychology of meaning (pp. 297-316). Washington, DC: American Psychological Association.

Routledge, C., Wildschut, T., Sedikides, C., Juhl, J., \& Arndt, J. (2012). The power of the past:

Nostalgia as a meaning-making resource. Memory, 20, 452-460.

doi:10.1080/09658211.2012.677452

Schaufeli, W. B., \& Bakker, A. B. (2004). Job demands, job resources, and their relationship with burnout and engagement: A multi-sample study. Journal of Organizational Behavior, 25, 293-315. doi:10.1002/job.248

Schaufeli, W. B., \& Buunk, B. P. (2003). Burnout: An overview of 25 years of research and theorizing. In M. J. Schabracq, J. A. M. Winnubst, \& C. L. Cooper (Eds.), The handbook of work and health psychology (pp. 383-428). Lexington, MA: Lexington Books.

Sedikides, C., \& Wildschut, T. (2016a). Past forward: Nostalgia as a motivational force. Trends in Cognitive Sciences, 20, 319-321. doi:10.1016/j.tics.2016.01.008

Sedikides, C., \& Wildschut, T. (2016b). Nostalgia: A bittersweet emotion that confers psychological health benefits. In J. Johnson \& A. Wood (Eds.), The Wiley handbook of positive clinical psychology (pp. 25-136). Hoboken, NJ: Wiley.

Sedikides, C., Wildschut, T., Arndt, J., \& Routledge, C. (2008). Nostalgia: past, present, and future. Current Directions in Psychological Science, 17, 304-307. doi:10.1111/j.14678721.2008.00595.x

Sedikides, C., Wildschut, T., Routledge, C., \& Arndt, J. (2015). Nostalgia counteracts selfdiscontinuity and restores self-continuity. European Journal of Social Psychology, 45, 52-61. doi:10.1002/ejsp.2073

Sedikides, C., Wildschut, T., Routledge, C., Arndt, J., Hepper, E. G., \& Zhou, X. (2015). To nostalgize: Mixing memory with affect and desire. Advances in Experimental Social Psychology, 51, 189-273. doi:10.1016/bs.aesp.2014.10.001

Sparks, J. R., \& Schenk, J. A. (2001). Explaining the effects of transformational leadership: An investigation of the effects of higher-order motives in multilevel marketing organizations. Journal of Organizational Behavior, 22, 849-869. doi:10.1002/job.116 
Spencer, S. J., Zanna, M., \& Fong, G. T. (2005). Establishing a causal chain: Why experiments are often more effective than mediational analyses in examining psychological processes. Journal of Personality and Social Psychology, 89, 845-851. doi:10.1037/0022-3514.89.6.845

Steel, R. P., \& Ovalle, N. K. (1984). A review and meta-analysis of research on the relationship between behavioral intentions and employee turnover. Journal of Applied Psychology, 69, 673-686. doi:10.1037/0021-9010.69.4.673

Steger, M. F., Dik, B. J., \& Duffy, R. D. (2012). Measuring meaningful work: the Work and Meaning Inventory (WAMI). Journal of Career Assessment, 20, 322-337. doi:10.1177/1069072711436160

Steger, M. F., Littman-Ovadia, H., Miller, M., Menger, L., \& Rothmann, S. (2013). Engaging in work even when it is meaningless: Positive affective disposition and meaningful work interact in relation to work engagement. Journal of Career Assessment, 21, 348-361. doi:10.1177/1069072712471517

Stephan, E., Sedikides, C., \& Wildschut, T. (2012). Mental travel into the past: Differentiating recollections of nostalgic, ordinary, and positive events. European Journal of Social Psychology, 42, 290-298. doi:10.1002/ejsp.1865

Stephan, E., Wildschut, T., Sedikides, C., Zhou, X., He, W., Routledge, C., Cheung, W. Y., \& Vingerhoets, A. J. J. M. (2014). The mnemonic mover: Nostalgia regulates avoidance and approach motivation. Emotion, 14, 545-561. doi:10.1037/a0035673

Strangleman, T. (1999). The nostalgia of organisations and the organisation of nostalgia: Past and present in the contemporary railway industry. Sociology, 33, 725-746. doi:10.1177/S0038038599000462

Tett, R. P., \& Meyer, J. P. (1993). Job satisfaction, organizational commitment, turnover intention, and turnover: path analyses based on meta- analytic findings. Personnel psychology, 46, 259293. doi:10.1111/j.1744-6570.1993.tb00874.x

The New Oxford Dictionary of English. (1998). (J. Pearsall, Ed.). Oxford, UK: Oxford University Press. 
Ton, Z., \& Huckman, R. S. (2008). Managing the impact of employee turnover on performance: The role of process conformance. Organization Science, 19, 56-68. doi:10.1287/orsc. 1070.0294

Trent, J., Lavelock, C., \& King, L. A. (2013). Processing fluency, positive affect, and meaning in life. Journal of Positive Psychology, 8, 135-139. doi:10.1080/17439760.2013.772220

Van Dick, R., Christ, O., Stellmacher, J., Wagner, U., Ahlswede, O., Grubba, C., .. \& \& Tissington, P. A. (2004). Should I stay or should I go? Explaining turnover intentions with organizational identification and job satisfaction. British Journal of Management, 15, 351-360. doi:10.1111/j.1467-8551.2004.00424.x

Van Dijke, M., Wildschut, T., Leunissen, J. M., \& Sedikides, C. (2015). Nostalgia buffers the negative impact of low procedural justice on cooperation. Organizational Behavior and Human Decision Processes, 127, 15-29. doi:10.1016/j.obhdp.2014.11.005

Van Tilburg, W. A. P., Igou, E. R., \& Sedikides, C. (2013). In search of meaningfulness: Nostalgia as an antidote to boredom. Emotion, 13, 450-461. doi:10.1037/a0030442

Verplanken, B. (2012). When bittersweet turns sour: Adverse effects of nostalgia on habitual worriers. European Journal of Social Psychology, 42, 285-289. doi: 10.1002/ejsp.1852

Vess, M., Arndt, J., Routledge, C., Sedikides, C., \& Wildschut, T. (2012). Nostalgia as a resource for the self. Self and Identity, 3, 273-284. doi:10.1080/15298868.2010.521452

Wildschut, T., Bruder, M., Robertson, S., Van Tilburg, A. P. W., \& Sedikides, C. (2014). Collective nostalgia: A group-level emotion that confers unique benefits on the group. Journal of Personality and Social Psychology, 107, 844-863. doi:10.1037/a0037760

Wildschut, T., Sedikides, C., Arndt, J., \& Routledge, C. (2006). Nostalgia: content, triggers, functions. Journal of Personality and Social Psychology, 91, 975-993. doi:10.1037/00223514.91.5.975

Wildschut, T., Sedikides, C., Routledge, C., Arndt, J., \& Cordaro, F. (2010). Nostalgia as a repository of social connectedness: The role of attachment-related avoidance. Journal of Personality and Social Psychology, 98, 573-586. doi:10.1037/a0017597

Williams, K. D. (2001). Ostracism: The power of silence. New York, NY: Guilford. 
Wright, T. A., Cropanzano, R., \& Meyer, D. G. (2004). State and trait correlates of job performance: A tale of two perspectives. Journal of Business and Psychology, 18, 365-383.

Wrzesniewski, A., Dutton, J. E., \& Debebe, G. (2003). Interpersonal sensemaking and the meaning of work. Research in Organizational Behavior, 25, 93-135. doi:10.1016/S01913085(03)25003-6

Wrzesniewski, A., McCauley, C., Rozin, P., \& Schwartz, B. (1997). Jobs, careers, and callings: People's relations to their work. Journal of Research in Personality, 31, 21-33. doi:10.1006/jrpe.1997.2162

Ylijoki, O. H. (2005). Academic nostalgia: A narrative approach to academic work. Human Relations, 58, 555-576. doi:10.1177/0018726705055963

Zhou, X., Sedikides, C., Wildschut, T., \& Gao, D. G. (2008). Counteracting Loneliness: On the Restorative Function of Nostalgia. Psychological Science, 19, 1023-1029. doi:10.1111/j.1467-9280.2008.02194.x

Zhou, X., Wildschut, T., Sedikides, C., Shi, K., \& Feng, C. (2012). Nostalgia: The gift that keeps on giving. Journal of Consumer Research, 39, 39-50. doi:10.1086/662199 


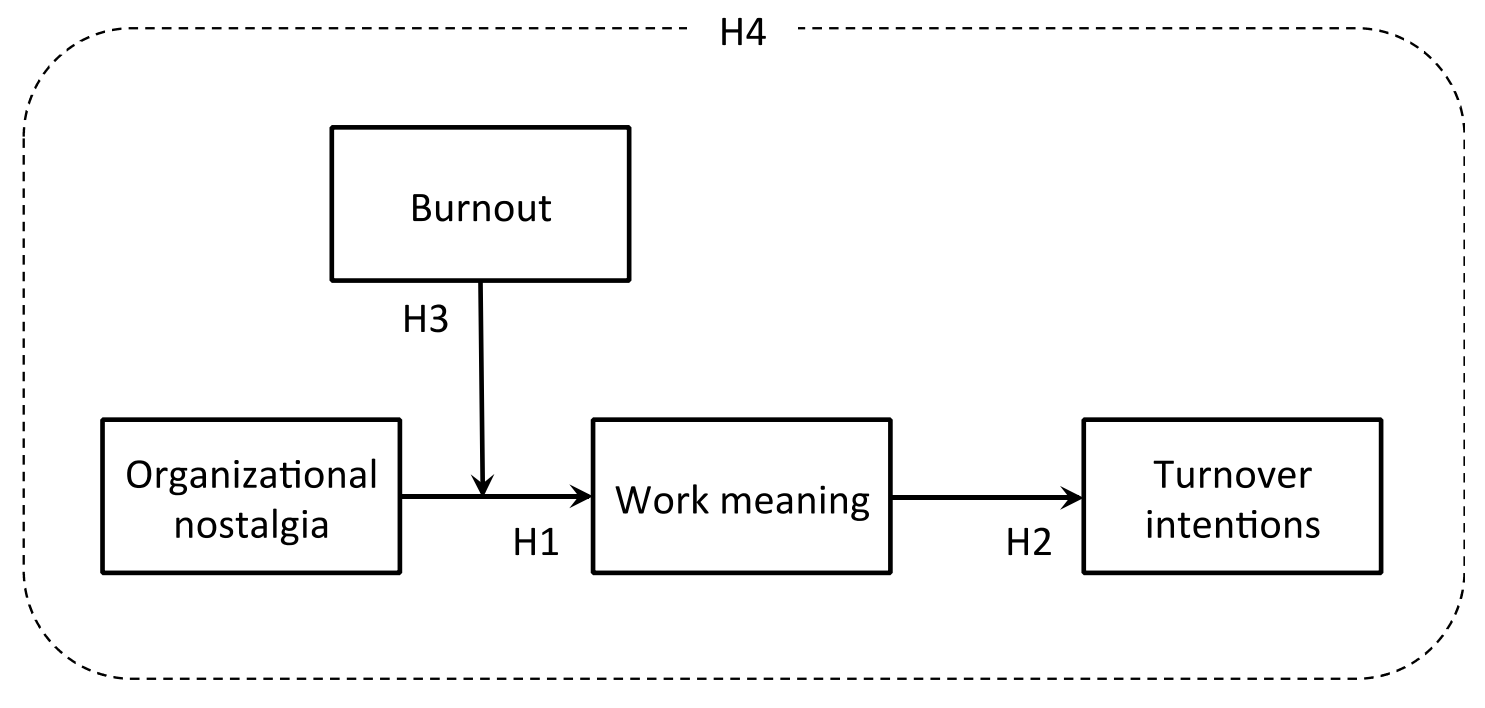

Figure 1. Graphical representation of the hypotheses. H1, H2, H3 = Hypothesis 1, 2, 3. Hypothesis 4 entails the full moderated mediation model. 

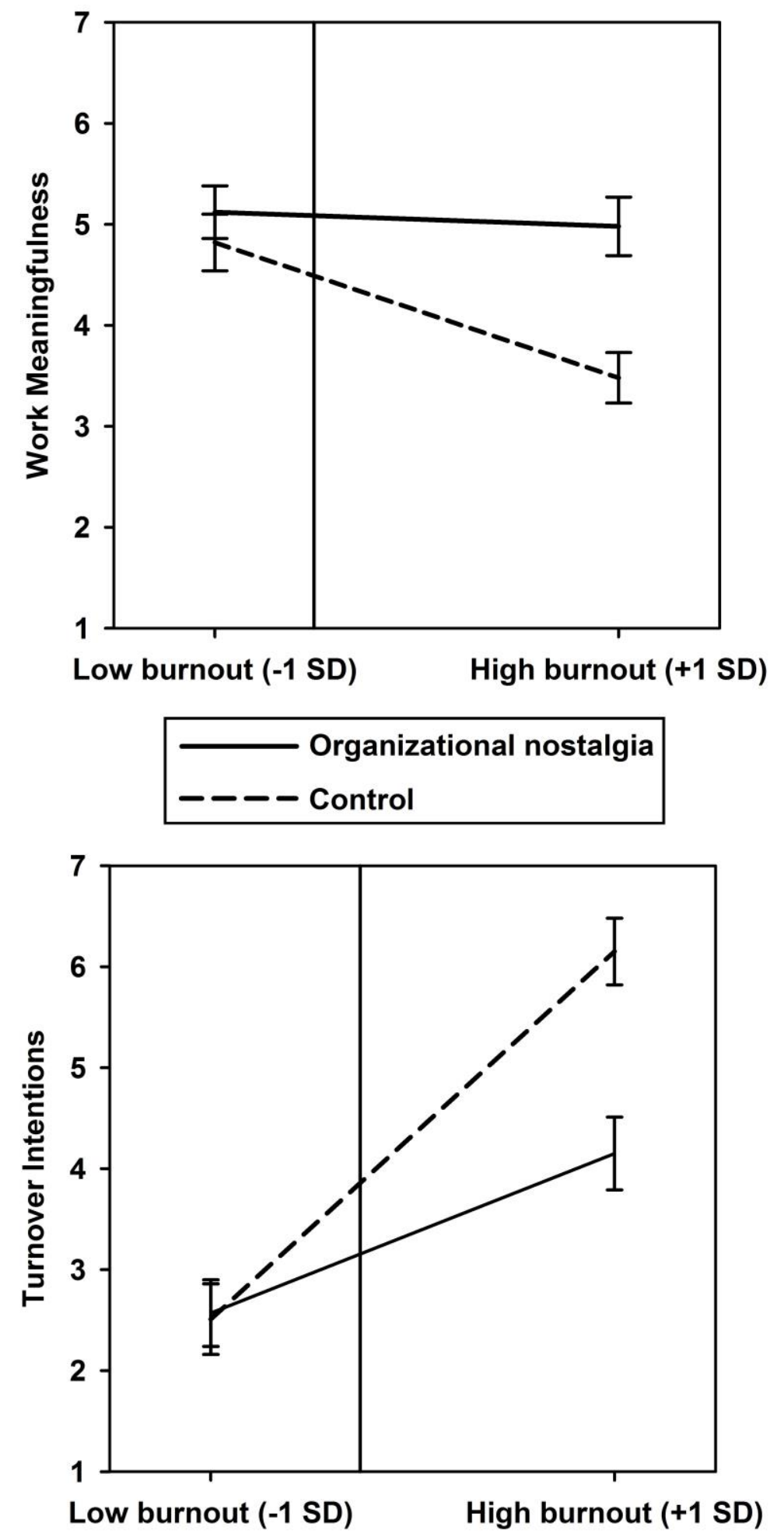

Figure 2. Interaction effects between organizational nostalgia and burnout on work meaning (upper panel) and turnover intentions (lower panel) in Study 3. The vertical reference lines identify the regions of significance for the effects of organizational nostalgia. Error bars represent standard errors. 

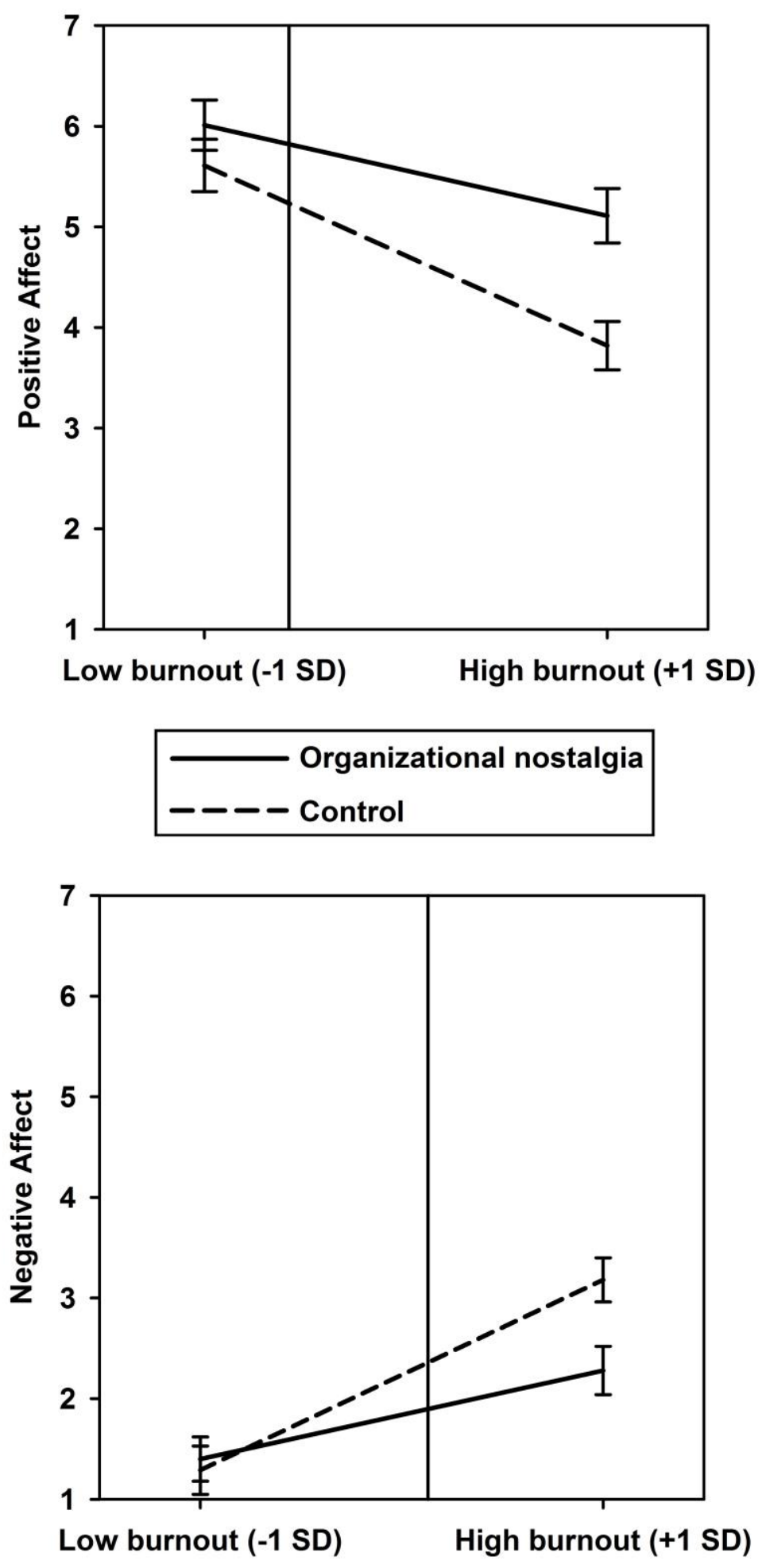

Figure 3. Interaction effects between organizational nostalgia and burnout on positive affect (upper panel) and negative affect (lower panel) in Study 3. The vertical reference lines identify the regions of significance for the effects of organizational nostalgia. Error bars represent standard errors. 


\author{
Appendix \\ Illustrations of Participant-Generated Narratives in Study 2
}

\title{
Organizational-Nostalgia Condition
}

\section{Narrative 1}

"A few years ago, my company had a Christmas party. They do this every year and employees bring their families to the party. This particular year was especially memorable. Everyone showed up to the party and a group of us had decorated the office really beautifully and really made the party come together well. Everyone had a great time. People were dancing and enjoying the food and socializing all night. It was nice to be with my coworkers outside of the normal work setting. We did a yankee swap, which was really fun and it was just a good night. Everyone was in a great mood and in the Christmas spirit. There was no drama and even people who didn't always get along well seemed to enjoy themselves."

\section{Narrative 2}

"I remember that my boss retired after being at the company for 35 years. He threw a party and we all cried for hours because he was the best boss ever. He did not want to leave but he was tired after so many years working."

\section{Control Condition}

\section{Narrative 1}

"Every Friday we get a shipment of food items to the store. We are required to take everything out of the walk-in and count what is left and what is being added. It usually takes around 45 minutes. We have to organize the walk-in with the older items in the front and the newer items further in the back. Out of date items must be removed and thrown away. This is a job that generally no on enjoys. So we usually leave it for someone who is new. It isn't difficult just busy work. I usually feel bored while doing the work. I don't have to think about anything just read labels and write things down. I usually look forward to being finished."

\section{Narrative 2}

"A person brought me a computer and says that it is very slow. After I had examined it I thought that up grading the memory would speed it up. I purchased the extra memory and installed it. Testing the computer showed that I was right and the computer is much faster in response. The last thing I did was to log all the information into my data base for future reference." 